Artigos

\title{
Exercício profissional e atividade ilícita em odontologia no Brasil
}

\section{Professional exercise and illicit activity in brazilian dentistry}

\author{
Ricardo Henrique Alves da Silva1', Arsenio Sales-Peres²
}

\begin{abstract}
Silva RHA, Sales-Peres A. Exercício profissional e atividade ilícita em odontologia no Brasil. Saúde, Ética \& Justiça. 2009;14(1):1-8.

Resumo: A atividade ilícita profissional ainda constitui uma preocupação na área odontológica, sendo observada de diversas formas na sociedade. O presente trabalho justifica-se por propiciar à classe odontológica e aos profissionais do Direito, bem como à comunidade em geral, uma melhor visão deste problema, permitindo um melhor posicionamento das autoridades pertinentes. Desta maneira, o estudo tem como objetivo realizar uma revisão de literatura abordando os aspectos referentes ao exercício profissional e à atividade ilícita em Odontologia, permeada pela análise das legislações e regulamentações pertinentes.
\end{abstract}

Descritores: Odontologia legal. Direito. Saúde pública.

INTRODUÇÃO

Prometo que ao exercer a arte de curar, mostrarme-ei sempre fiel aos preceitos da honestidade, da caridade e da ciência. Penetrando no interio dos lares, meus olhos serão cegos e minha língua calará os segredos que me forem revelados, o que terei como preceitos de honra; nunca me servirei de minha profissão para corromper os costumes ou favorecer o crime. Se eu cumprir este juramento com fidelidade, goze para sempre a minha vida e a minha arte de boa reputação entre os homens; se o infringir ou dele me afastar, suceda-me o contrário ${ }^{29}$.

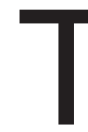

ranscrito acima está o Juramento da Odontologia, perante o qual todos os profissionais da área odontológica elevaram seu braço direito e juraram cumpri-lo. A Odontolo- gia evoluiu muito desde a sua constituição como profissão legalmente reconhecida, tendo não apenas um juramento a seguir, mas sim toda uma Deontologia específica, com o intuito de normalizar e permitir uma Odontologia de qualidade para toda a população.

Desta forma, este trabalho apresenta-se como uma singela contribuição ao entendimento dos aspectos legais que envolvem o exercício profissional e a atividade ilícita em Odontologia, seja através da legislação promulgada pelo Governo ou pelas regulamentações dos Conselhos, visando esclarecer tais aspectos aos profissionais da área odontológica, bem como aos do Direito.

Côrrea ${ }^{21}$ utiliza uma citação do Papa Pio XII ao descrever a Odontologia como "uma profissão que

1 Professor Doutor em Odontologia Legal e Deontologia da Faculdade de Odontologia de Ribeirão Preto, USP

2 Professor Livre Docente de Deontologia e Odontologia Legal da Faculdade de Odontologia de Bauru, USP.

Endereço PARA Correspondência: Dr. Ricardo Henrique Alves da Silva. FORP - USP. Departamento de Clínica Infantil, Odontologia Preventiva e Social. Avenida do Café, s/n, Bairro Monte Alegre, Ribeirão Preto-SP, CEP: 14040-904. E-mail: ricardohenrique@usp.br 
Silva RHA, Sales-Peres A. Exercício profissional e atividade ilícita em odontologia no Brasil.

exige, dos que a ela se dedicam, o senso estético de um artista, a destreza manual de um cirurgião, os conhecimentos científicos de um médico e a paciência de um monge". Porém, se analisarmos a atual realidade de mercado da nação brasileira, visualizando que o número de processos contra profissionais da área de saúde, dentre eles o cirurgião-dentista, vem crescendo, seria digno de nota acrescentar, também, o discernimento da legislação de um jurista.

E, sendo a Odontologia uma das profissões intrinsecamente ligadas à Saúde Pública, a violação das suas exigências não poderia deixar de caracterizar-se como crime. Além disso, notase uma aparente falta de vontade, por parte dos profissionais, em compreender os objetivos mais específicos da inter-relação envolvendo a Odontologia e o Direito ${ }^{33}$.

Desta maneira, utilizando as palavras de Calvielli ${ }^{15}$, temos que:

os tratadistas do Direito Penal reservam poucas linhas de seus comentários para o exercício ilegal da Medicina, Odontologia e Farmácia, e o fazem sem considerar, principalmente, a evolução e transformações sofridas por essas profissões nos últimos anos. Por sua vez, os cirurgiões-dentistas agem como se o exercício de sua profissão só eles dissesse respeito, desconhecendo, com raras exceções, que inúmeras conseqüências de suas atividades encontram-se previstas como infrações penais.

Assim sendo, esperamos contribuir para o entendimento de tão vasto assunto, possibilitar um crescimento para a classe odontológica e, conseqüentemente, para toda a sociedade brasileira buscando uma Odontologia exemplar, conforme relata Phillips ${ }^{31}$ :

Para cumprir suas responsabilidades com a sociedade e sobreviver como profissão, a Odontologia necessita dos seguintes requisitos: honestidade, integridade, independência profissional, alta qualidade de prestação de serviços, estudo continuado, expansão das pesquisas odontológicas, aplicação clínica das pesquisas e observação do Código de Ética

\section{O Exercício Profissional da Odontologia no Brasil}

Daruge e Massini22 colocam que os atos humanos devem sempre ser ou estar de acordo com os preceitos legais. Nessa vertente, Calvielli ${ }^{15}$ comenta que em muitos países, principalmente da América Latina, o número de pessoas não qualificadas, isto é, que exercem a Odontologia sem a devida autorização legal, chega a exceder, em determinadas localidades, o número de cirurgiõesdentistas capacitados legalmente.

Centenaro $^{17}$ afirma que, no Brasil, esse fato também pode ser constatado em algumas localidades, haja vista que o Código Penal Brasileiro tudo permite e nada impede, já que é necessário, além do flagrante, ainda provar que o sujeito pratica esse crime todos os dias e não eventualmente. E, para a configuração de crime, conforme exposto acima, França ${ }^{26}$ anuncia que é exigida a habitualidade, não podendo caracterizálo apenas um ato esporádico, pois é difícil excluir alguém que, pelo menos uma vez, não tenha feito um diagnóstico ou prescrito um medicamento.

Ao realizar uma incursão histórica referente à regulamentação do exercício da Odontologia no Brasil, Daruge e Massini22 expõem as etapas dessa regulamentação: a primeira regulamentação referese à Reforma do Regimento de Ofício de cirurgiãodentista elaborada em 1631. Posteriormente, em 1743 , foi criada a Carta de Ofício para a prática de cirurgia dentária. Em 6 de agosto de 1802 foi baixada a Carta de Comissão, a primeira a prever multa de dois mil réis para quem exercesse a prática odontológica sem "Carta" ou sem a condição de aprovado. A seguir, o Decreto no 9.311 , de 25 de outubro de 1884, considerava crime o exercício da Odontologia por todos aqueles que não tivessem obedecido às normas daquele decreto.

Após esta, nenhuma outra legislação reguladora foi editada até 1932, quando é redigido o Decreto no 20.9313 que regulamentou a fiscalização do exercício da Medicina, da Odontologia, da Medicina Veterinária e das profissões de Farmacêutico, Parteira e Enfermeira, prevendo, a partir daí, penalidades como a apreensão do material encontrado:

"Do Exercício da Odontologia

Art. 30 - O cirurgião-dentista somente poderá prescrever agentes anestésicos de uso tópico e medicamento de uso externo para os casos restritos de sua especialidade.

Art. 31 - Ao cirurgião-dentista é vedado praticar intervencões cirúrgicas, que exijam conhecimentos estranhos à sua profissão, bem como permitir o 
exercício da clínica odontológica, em seu consultório a indivíduo não legalmente habilitado para exercê-la. Art. 32 - O material existente em consultório dentário, cujo funcionamento não esteja autorizado pela autoridade sanitária ou que seja utilizado por quem não tiver diploma registrado no Departamento Nacional de Saúde Pública, será apreendido e remetido para o depósito público"

Vinte anos depois, uma nova legislação regulamentando o exercício profissional do cirurgiãodentista é criada, a Lei no 1.314 , de 17 de janeiro de $1951^{1,27}$, representando um avanço, pois exigia duas condições fundamentais, o diploma (que deveria ser expedido por estabelecimento de ensino oficial ou reconhecido) e o registro do mesmo nos órgãos competentes.

Em 1964, é regulamentada a Lei no ${ }^{4} .324$, estabelecendo o Conselho Federal de Odontologia, órgão normativo da profissão no país, do qual emanam as resoluções que devem orientar a atuação dos Conselhos Regionais, aos quais se subordinam todos os profissionais ${ }^{21}$. E, finalmente, chega-se à legislação em vigor atualmente, a Lei no 5.08110 , de 24 de agosto de 1966, adquirindo, a Odontologia, ampla autonomia no que concerne ao seu exercício legal.

Vale ressaltar que, de acordo com Calvielli15, apesar de toda a evolução transcrita acima, a Lei no 1.314, de 17 de Janeiro de 1951, é considerada a primeira lei regulamentar da profissão, delimitando que o exercício ilegal da Odontologia pode consubstanciar-se de duas maneiras: pela prática de atos próprios de cirurgião-dentista sem autorização legal; ou excedendo-se os limites da própria profissão ${ }^{13}$.

$E$, partindo dos dizeres de Bernaba $^{1}$, ao afirmar que os profissionais militantes do campo biomédico muitas vezes ficam alheios aos problemas jurídicos referentes à sua atividade profissional, e pelo que estatui a própria lei, ou seja, que ninguém pode alegar erro ou ignorância, torna-se importante abordar, de maneira sucinta, os aspectos jurídicos referentes ao exercício da profissão odontológica.

Se errar é humano, quando o cirurgião-dentista comete um erro em sua prática profissional, isto pode implicar em penalidades como a cassação do registro profissional, indenização e, até mesmo, detenção ${ }^{24}$. A Lei $\mathrm{n}^{\circ} \mathbf{5 . 0 8 1 1 0}$, de 24 de agosto de 1966, estabelece que:
“Art. 2․ - O exercício da Odontologia no território nacionalsóé permitido ao cirurgião-dentistahabilitado por escola ou faculdade oficial ou reconhecida, após o registro do diploma na Diretoria do Ensino Superior, no Serviço Nacional de Fiscalização da Odontologia, na Repartição Sanitária Estadual competente e inscrição no Conselho Regional de Odontologia sob cuja jurisdição se achar o local de sua atividade.

Art. 3․ - Poderão exercer a Odontologia no território nacional os habilitados por escolas estrangeiras, após a revalidação do diploma e satisfeitas as demais exigências do artigo anterior.

Art. 4ㅇ․ - É assegurado o direito do exercício da Odontologia, com as restrições legais, ao diplomado nas condições mencionadas no Decreto-Lei nำ 7.718 , de 09 de julho de 1945, que regularmente se tenha habilitado para o exercício profissional, somente nos limites territoriais do Estado onde funcionou a escola ou faculdade que o diplomou".

Esmiuçando a questão da autorização legal e trazendo à tona os conhecimentos oriundos dos ensinamentos de Calvielli ${ }^{14}$ temos, com referência ao artigo $2^{\circ}$ da Lei $n^{\circ} 5.081 / 66$, que algumas modificações estruturais e administrativas ocorreram nos órgão oficiais citados no artigo.

Desta forma, primeiramente é necessário um curso de graduação em escola oficial ou reconhecida, sendo este reconhecimento realizado pelo Governo Federal, obtendo-se a habilitação profissional. O diploma obtido atualmente é registrado pelas Universidades federais ou estaduais, de acordo com a região em que atuam, não existindo mais a Diretoria de Ensino Superior.

A partir daí, o profissional necessita da habilitação legal, ou seja, registro no Conselho Federal de Odontologia (em substituição ao Serviço Nacional de Fiscalização da Odontologia), nos Escritórios Regionais de Saúde (ERSA), caso pretenda exercer clínica odontológica, e, finalmente, no Conselho Regional de Odontologia sob cuja jurisdição se achar o local de sua atividade.

Frente ao que diz o artigo $2^{\circ}$, complementado pelo artigo $3^{\circ}$ da Lei $n^{\circ} 5.081 / 66$, poderão exercer a Odontologia no Brasil ${ }^{15}$ :

- Brasileiros e estrangeiros diplomados no Brasil por curso de Odontologia reconhecido pelo Ministério da Educação;

- Até 1998, os estrangeiros diplomados no Brasil por curso de Odontologia reconhecido pelo Ministério da Educação, beneficiados pelo Programa de Estudante-Convênio (PEC), coordenado pelos 
Silva RHA, Sales-Peres A. Exercício profissional e atividade ilícita em odontologia no Brasil.

Ministérios das Relações Exteriores e da Educação, porém ficou normalizado pelo Protocolo ${ }^{12}$ publicado em 07 de abril de 1998, em sua cláusula 23, que o estudante-convênio deverá retornar ao seu país de origem no prazo de até três meses a partir da colação de grau;

- Estrangeiros diplomados no Brasil por curso de Odontologia reconhecido pelo Ministério da Educação, beneficiados pelas matrículas de cortesia, nos termos do Decreto Federal no 89.758 de 06 de junho de 1984, para funcionários estrangeiros de missões diplomáticas, repartições consulares e organismos internacionais, bem como seus dependentes legais;

-Diplomados por instituições de ensino superior de outros países cujos diplomas tenham sido revalidados no Brasil, sejam eles estrangeiros ou brasileiros;

- Até 1999, os diplomados por instituições de ensino superior sediadas nos países que ratificaram a convenção regional sobre o reconhecimento de estudos, títulos e diplomas de ensino superior na América Latina e no Caribe, aprovada pelo Decreto Federal $n^{\circ}$ 80.4196, de 27 de setembro de 1977 não necessitavam de revalidação do diploma. Faziam parte deste acordo os diplomados no Panamá, México, Chile, Venezuela, Cuba, Colômbia, El Salvador, Equador, Suriname, Aruba, Curaçao, Santa Sé, lugoslávia e Holanda, cabendo aos possuidores destes diplomas, quando estrangeiros, terem uma situação de permanência no país. O Decreto $80.429 / 77$ foi revogado pelo Decreto no 3.0075 , de 30 de março de 1999;

- Diplomados por instituições de ensino superior de Portugal, por força do Acordo Cultural assinado em 07 de setembro de 1966 e Protocolo Adicional aprovado pelo Decreto Legislativo no 60, de 17 de agosto de 1971 e promulgado pelo Decreto $\mathrm{n}^{\circ}$ 69.271, de 23 de setembro de 1971;

- Cirurgiões-dentistas estrangeiros, portadores de contrato de trabalho visado pelo Ministério do Trabalho ou de comprovação de prestação de serviço ao governo brasileiro, pelo prazo de dois anos.

Todos os dispositivos acima citados vêm da preocupação das autoridades brasileiras com o exercício profissional por pessoa efetivamente habilitada, de fato e de direito, de forma a afastar toda a espécie de charlatanismo que venha a colocar em risco a segurança e a saúde pública ${ }^{22}$.

O artigo $4^{\circ}$ da Lei $n^{\circ}$ 5.081/6610 abre uma exceção para os profissionais diplomados pelo Decreto-Lei
№ 7.718 , de 09 de julho de 1945, ou seja, aqueles que foram diplomados por escolas reconhecidas apenas pelos governos estaduais, respeitando-se o princípio constitucional do direito adquirido. Estes profissionais não têm autorização para exercer suas atividades em outros Estados da Federação, podendo exercê-la somente naquele onde funcionou o curso realizado para a obtenção do diploma ${ }^{22}$.

Finalizando a questão da autorização legal, fazse importante salientar a questão dos "dentistaspráticos" ou "práticos licenciados". Conforme relata Calvielli ${ }^{13}$, entre 1931 e 1933 foram editados decretos garantindo aos profissionais acima citados a possibilidade de pleitear a inscrição junto aos órgãos de Saúde Pública, a fim de continuarem a exercer seu ofício mediante determinadas restrições. A data limite para a concessão foi fixada como 30 de junho de 1934, pelo Decreto no $23.5404,25$, de 04 de dezembro de 1933:

"O Chefe do Governo Provisório da República dos Estados Unidos do Brasil, usando das atribuições que Ihe confere o art. 1을 do Decreto-Lei no 19.398 , de 11 de Novembro de 1930, decreta:

Art. 1o - Fica limitado até 30 de junho de 1934 o prazo dos favores concedidos pelos Decretos $\mathrm{n}^{\circ}$ 20.862 e 20.877, respectivamente de 28 e 30 de dezembro de 1931, 21.073, de 22 de fevereiro de 1932, e 22.501, de 27 de fevereiro de 1933.

Art. $2^{\circ}$ - Revogam-se as disposições em contrário".

Sendo assim, considerando que já se passaram mais de 70 anos da data fixada, aqueles que poderiam dela se beneficiar devem contar, atualmente, mais de 90 anos, o que torna inadmissível a presença do "dentista prático" ou "prático licenciado" abaixo dessa faixa etária.

Ainda dentro da delimitação do exercício profissional da Odontologia no Brasil, existe a questão da não extrapolação das competências firmadas, sendo estabelecida, pela Lei $\mathrm{n}^{\circ}$ 5.081/6610:

"Art. 6o - Compete ao cirurgião-dentista:

I - Praticar todos os atos pertinentes à Odontologia, decorrentes de conhecimentos adquiridos em curso regular ou em cursos de pós-graduação;

II - Prescrever e aplicar especialidades farmacêuticas de uso interno e externo, indicadas em Odontologia;

III - Atestar, no setor de sua atividade profissional, estados mórbidos e outros inclusive, para justificação de faltas ao emprego; 
IV - Proceder à perícia odontolegal em foro civil, criminal, trabalhista e em sede administrativa;

$\mathrm{V}$ - Aplicar anestesia local e troncular;

$\mathrm{VI}$ - Empregar a analgesia e hipnose, desde que comprovadamente habilitado, quando constituírem meios eficazes para o tratamento;

VII - Manter, anexo ao consultório, laboratório de prótese, aparelhagem e instalação adequadas para pesquisas e análises clínicas, relacionadas com os casos específicos de sua especialidade, bem como aparelhos de Raios X, para diagnóstico, e aparelhagem de Fisioterapia;

VIII - Prescrever e aplicar medicação de urgência no caso de acidentes graves que comprometam a vida e a saúde do paciente;

IX - Utilizar, no exercício da função de peritoodontólogo, em casos de necropsia, as vias de acesso do pescoço e da cabeça".

Verifica-se que a lei deu ampla competência ao cirurgião-dentista generalista, sempre necessário em uma nação de extensão continental como o Brasil. Contudo, exige para o que se consubstanciou denominar de "especialista", capacidade muito mais ampliada em face da educação continuada. Desta forma, o CFO estatuiu as especialidades odontológicas e definiu, em cada uma delas, os atos de competência do cirurgião-dentista ${ }^{32}$. Atualmente, a Odontologia conta com 19 especialidades e cada uma delas, seguindo as diretrizes da Lei $\mathrm{n}^{\circ}$ $5.081 / 6610$, apresenta competências específicas delimitadas pela Resolução CFO 22/200120.

Importante salientar que a regulamentação da Odontologia e do seu exercício profissional não se esgota nos limites estritos da Lei $n^{\circ}=5.081 / 66$. Ela é muito mais ampla, contendo disposições em outros diplomas legais e nos atos normativos do CFO, bem como em atos executivos dos Conselhos Regionais ${ }^{21}$.

Graça-Leite ${ }^{28}$ comenta que é extremamente vantajoso e necessário o conhecimento da legislação profissional no exercício das atividades laborativas, permitindo segurança e tranqüilidade ao cirurgião-dentista, porém trata-se de fato pouco comum em profissões liberais.

A partir das disposições legais vigentes, em associação com as normas éticas, o exercício da Odontologia passa a adquirir majestade científica e se projeta como atividade social ${ }^{32}$.

Atividade ilícita profissional em Odontologia no Brasil

Juntamente com a Lei ํo 5081/66, prevêem- se condutas e ações contra o cirurgião-dentista brasileiro, podendo este ser julgado em duas esferas de responsabilidade: a administrativa e a judicial (envolvendo ações penais e civis) ${ }^{24}$. Daruge e Massini ${ }^{22}$ declaram em seu trabalho os ensinamentos do consagrado civilista Washington de Barros Monteiro:

"A violação de um direito pode configurar ofensa à sociedade pelo dano pessoal e pelo dano material. No primeiro caso, existe o delito penal, consistente na violação de uma lei penal, o que induz responsabilidade penal; no segundo caso existe o delito civil, consistente na violação de um direito subjetivo privado, o que induz responsabilidade civil. Pode suceder ainda que o fato atentatório da lei penal viole também um direito privado. Nesse caso, subsistirão concomitantemente as duas responsabilidades, a penal e a civil”.

Inicialmente, o direito a exercer uma determinada profissão é estabelecido pela Constituição da República Federativa do Brasil $^{2}$, proclamada em 1988 e que estatui, em seu artigo 5으, inciso XIII: "É livre o exercício de qualquer trabalho, ofício ou profissão, atendidas as qualificações profissionais que a lei estabelecer". Assim, conforme observado, o princípio constitucional de pleno exercício de uma profissão não é garantia para que qualquer um possa entregar-se livremente a uma atividade profissional, mas o direito de exercê-la desde que se atenda ao estabelecido na lei, ou seja, possuir autorização, competência e legitimidade ${ }^{26}$.

A partir desta colocação, é necessário o estabelecimento de penas para os casos de infringência das leis que regulamentam as profissões. No caso da Odontologia, o exercício ilegal é previsto no Código Penal Brasileiro ${ }^{8}$, em seu artigo 282:

"Art. 282 - Exercer, ainda que a título gratuito, a profissão de médico, dentista ou farmacêutico, sem autorização legal ou excedendo-Ihe os limites.

Pena - detenção, de seis meses a dois anos.

Parágrafo único - Se o crime é praticado com o fim de lucro, aplica-se também multa."

Conforme cita Calvielli15, a proibição do exercício das profissões da saúde por indivíduo sem autorização para fazê-lo é das mais antigas nas legislações e acompanha, de certa forma, as etapas de evolução pelas quais passaram essas profissões. Segundo a autora, a infração do artigo 
Silva RHA, Sales-Peres A. Exercício profissional e atividade ilícita em odontologia no Brasil.

282 comporta duas modalidades: na primeira, o sujeito ativo pratica atos próprios de profissional, porém sem autorização legal; na segunda, embora capacitado legalmente, excede os limites da própria profissão.

Menezes $^{30}$ discorre que, em se tratando de um cirurgião-dentista, podemos enumerar as seguintes condições em que é considerado ilegal o exercício da profissão: 1) Após ter concluído o curso sem, todavia, ter recebido o diploma; 2) Após ter recebido o diploma sem, contudo, proceder aos registros exigidos por lei; 3) Quando diplomado por escola estrangeira, exerce a sua atividade profissional no Brasil sem, entretanto, proceder à revalidação do diploma e aos registros que se fizerem necessários; 4) Tendo sido apenado com suspensão do exercício profissional, continuar exercendo sua atividade odontológica durante o período de suspensão; 5) Tendo se transferido para outro Estado sem providenciar, dentro do prazo de 90 dias, a transferência de sua inscrição para o Conselho Regional sob cuja jurisdição passou a atuar; 6) Praticar intervenção fora da área de atuação de competência do cirurgião-dentista.

Além das formas acima citadas que dizem respeito exclusivamente a cirurgiões-dentistas, as atividades de indivíduos que não possuam a formação em cursos regulares de Odontologia e que estejam executando serviços que sejam exclusivos de cirurgião-dentista ou alegando serem cirurgiõesdentistas configuram-se, também, como exercício ilegal da profissão.

De acordo com França ${ }^{26}$, o que se procura evitar pela sanção penal, no exercício ilegal, é que a saúde pública venha a ser ameaçada por pessoas não-qualificadas e incompetentes, sendo suficiente apenas o perigo para configurar-se o crime, não exigindo a lei que venha a consumar-se qualquer lesão ou malefício.

Sendo assim, no que tange ao artigo 282 do Código Penal Brasileiro, a falta de autorização legal pode ser configurada por algumas situações, como a atuação de auxiliar em Odontologia, no caso do Técnico em Prótese Dentária (TPD), sem a prescrição, supervisão e fiscalização do cirurgiãodentista. E, no caso de Técnico em Higiene Dental (THD) e Auxiliar de Consultório Dentário (ACD), sem a supervisão direta do cirurgião-dentista.

Desde a Resolução CFO 185/9319, cada uma das profissões auxiliares da Odontologia possui as suas competências, a fim de não incorrerem em exercício ilegal da profissão. Também é importante ressaltar que o acadêmico de Odontologia só pode praticar seu aprendizado em ambulatórios ou clínicas da faculdade, e sempre sob a supervisão do pessoal docente ${ }^{15}$.

Frente à questão dos estágios realizados por estudantes de Odontologia que buscam seu aperfeiçoamento profissional, Campos $^{16}$ afirma que tal situação é regida pelo Decreto $\mathrm{n}^{\circ}$ 87.4977, que regulamenta a Lei $n \div 6.49411$, de 07 de Dezembro de 1977, e também apresenta regulamentação pelo Conselho Federal de Odontologia através da Decisão CFO no $25 / 8418$, delimitando responsabilidades, momentos e formas de realização de estágio por acadêmicos.

Referente, ainda, ao Código Penal Brasileiro, dois outros aspectos são enquadrados como atividade ilícita ${ }^{30}$. Em primeiro lugar, o charlatanismo, regido pelo artigo 283 do Código Penal Brasileiro ${ }^{8}$, conforme segue "Art. 283 - Inculcar ou anunciar cura por meio secreto ou infalível: Pena - detenção de três meses a um ano, e multa."

Graça-Leite ${ }^{28}$ explana que inculcar é informar sobre alguma coisa, recomendar; anunciar é dar notícia de, publicar. Sendo assim, se o profissional torna pública por qualquer meio de divulgação em massa ou através de pequenos grupos de conversa, informação a respeito de tratamentos secretos ou infalíveis, estará incidindo em crime de charlatanismo. Em suma, o autor expõe que:

$$
\begin{aligned}
& \text { "O fator econômico, encontrando um terreno } \\
& \text { predisposto (fragilidade moral), determina, } \\
& \text { comumente, o surto de uma doença profissional que } \\
& \text { se chama charlatanismo, de profunda e desastrosa } \\
& \text { repercussão social. Por outro lado, compete ao } \\
& \text { Estado, um dos maiores responsáveis pela crise } \\
& \text { que asfixia a Odontologia, criar novas condições de } \\
& \text { trabalho e de assistência para o cirurgião-dentista, } \\
& \text { o que viria favorecer a redução, senão a extinção, } \\
& \text { do terrível mal do exercício charlatanesco da } \\
& \text { profissão." }
\end{aligned}
$$

Segundo Menezes ${ }^{30}$, charlatão não é aquele que se aventura ao exercício de uma profissão de saúde sem habilitação profissional, não é sinônimo de empírico ou falso profissional, mas sim aquele que usa de mentira, de falsidade, agindo de maneira inescrupulosa para enganar seus pacientes. De acordo com Ferreira ${ }^{23}$, charlatão é o explorador da boa-fé do povo, impostor, trapaceiro. 
Exemplificando, o charlatanismo pode configurarse pelas seguintes situações: diagnóstico falso ou exagerado, realização de intervenções desnecessárias, garantia de cura, exploração mercantilista da publicidade, dentre outras ${ }^{30}$.

O outro aspecto da atividade ilícita refere-se à figura do curandeirismo, no artigo 284 do Código Penal Brasileiro8:

"Art. 284 - Exercer o curandeirismo:

I - Prescrevendo, administrando ou aplicando habitualmente qualquer substância.

II - Usando gestos, palavras ou qualquer outro meio. III - Fazendo diagnósticos.

Pena: detenção de seis meses a dois anos. Parágrafo único: se o crime é praticado mediante remuneração, o agente também fica sujeito a multa".

E, apenas para finalizar, além das normativas já observadas, Bernaba ${ }^{1}$ cita, em seu trabalho sobre os aspectos penais quanto ao exercício ilegal, a Lei das Contravenções Penais, no que concerne à organização da atividade laborativa: "Art. 47-Exercer profissão ou atividade econômica ou anunciar que a exerce, sem preencher as condições a que por lei está subordinado o seu exercício. Pena: prisão simples, de quinze dias a três meses, ou multa."

\section{Considerações Finais}

Observa-se que o assunto exercício profissional e atividade ilícita em Odontologia interessa tanto a cirurgiões-dentistas quanto a profissionais da área do Direito, reafirmando a necessidade de profissionais que militem na área de Odontologia Legal a fim de auxiliar a Justiça, esclarecendo os pontos devidos.

Silva RHA, Sales-Peres A. Professional exercise and illicit activity in brazilian dentistry. Saúde, Ética \& Justiça. 2009;14(1):1-8

Авstract: The illegal professional activity still remains a concern in Dentistry, as it is observed in a number of different forms in the society. This study presents a broader view of this problem, which can be useful for the Dentistry and Law Science communities, as well as to the general community, inviting to think about a new attitude, specially regarding authorities' behavior. In this sense, the study aims to review the literature related to aspects of the professional exercise and illicit activity in Dentistry, analyzing laws and rules that focus on this matter.

KeYwords: Forensic dentistry. Law science. Public health.

\section{REFERÊNCIAS}

1. Bernaba JM. Aspectos penais quanto ao exercício ilegal da odontologia. Rev Assoc Paul Cir Dent. 1979; 33(5):364-9.

2. Brasil. Constituição da República Federativa do Brasil. 05 out. 1988.

3. Brasil. Decreto $\mathrm{n}-20.931$ : regula e fiscaliza o exercício da medicina, da odontologia, da medicina veterinária e das profissões de farmacêutico, parteira e enfermeira, no Brasil, e estabelece penas. 11 jan. 1932

4. Brasil. Decreto oo 23.540: limita, até 30 de junho de 1934, os favores concedidos pelos decretos ns. 20.862 e 20.877 , respectivamente de 28 e de 30 de dezembro de 1931, 21.073, de 22 de fevereiro de 1932, e 22.501, de 27 de fevereiro de 1931. $04 \mathrm{dez}$. 1933.
5. Brasil. Decreto o 3.007: revoga o decreto no 80.419 , de 27 de setembro de 1977, que dispõe sobre a execução da convenção regional sobre reconhecimento de estudos, títulos e diplomas de ensino superior na América Latina e no Caribe. 30 mar. 1999.

6. Brasil. Decreto oํ 80.419: promulga a convenção regional sobre reconhecimento de estudos, títulos e diplomas de ensino superior na América Latina e no Caribe. 27 set. 1977.

7. Brasil. Decreto no 87.497: regulamenta a lei no 6.494 , de 07 de dezembro de 1977. 18 ago. 1982.

8. Brasil. Decreto-Lei no 2.848: Código Penal Brasileiro. $07 \mathrm{dez} .1940$.

9. Brasil. Lei oo 1.314: regulamenta o exercício profissional dos cirurgiões-dentistas. 17 jan. 1951.

10. Brasil. Lei oㅡ 5081: regula o exercício da odontologia. 
Silva RHA, Sales-Peres A. Exercício profissional e atividade ilícita em odontologia no Brasil.

24 ago. 1966.

11. Brasil. Lei no 6.494: dispõe sobre o estágio de estudantes de estabelecimentos de ensino superior e de $2^{\circ}$ grau regular e supletivo nos limites que especifica e dá outras providências. 07 dez. 1977.

12. Brasil. Protocolo que entre si celebram o Ministério das Relações Exteriores e o Ministério da Educação e do Desporto, para regulamentar o Programa de Estudantes-Convênio de Graduação. 20 dez. 1996.

13. Calvielli ITP. Exercício ilícito da odontologia. In: Silva M. Compêndio de odontologia legal. Rio de Janeiro: Medsi; 1997. p.39-49

14. Calvielli ITP. Lei $\mathrm{n}^{\circ} \mathbf{5 . 0 8 1}$, de 24 de agosto de 1966 regulamenta o exercício da odontologia no Brasil. In: Silva M. Compêndio de odontologia legal. Rio de Janeiro: Medsi; 1997. p.15-38.

15. Calvielli ITP. O exercício ilegal da odontologia, no Brasil [Dissertação]. São Paulo: Faculdade de Direito, Universidade de São Paulo, 1993.

16. Campos A. O profissional da área odontológica Brasília: Centro Gráfico do Senado Federal; 1986.

17. Centenaro WL. Odontologia: profissão de ilegais [Citado em 20 dez. 2004]. Disponível em: http://www. malthus.com. br/artigos.asp?id=57.

18. Conselho Federal de Odontologia. Decisão CFO25/84, 25 out. 1984

19. Conselho Federal de Odontologia. Resolução CFO185/93: aprova a consolidação das normas para procedimentos nos conselhos de odontologia e revoga a resolução CFO-155/84, 26 abr. 1993.

20. Conselho Federal de Odontologia. Resolução CFO22/2001: baixa normas sobre anúncio e exercício das especialidades odontológicas e sobre cursos de especialização, revogando as redações do capítulo VIII, título I; capítulos I, II e III, título III, das normas aprovadas pela resolução CFO-185/93, alterada pela resolução CFO-198/95, 27 dez. 2001.

21. Côrrea R. Comentários e anotações sobre a regulamentação da odontologia. In: Corrêa $R$
Regulamentação da odontologia. Curitiba: Instituto Paranaense de Estudos Superiores; 1976. p.07-39.

22. Daruge E, Massini N. Exercício lícito da odontologia no Brasil. In: Daruge E. Direitos profissionais na odontologia. São Paulo: Saraiva; 1978. p.401-9.

23. Ferreira $A B$ de $H$. Dicionário Aurélio básico da língua portuguesa. Rio de Janeiro: Nova Fronteira; 1995. p.145.

24. Ferreira RA. No banco dos réus. Rev Assoc Paul Cir Dent. 1995;49(4):258-67.

25. Fortuna A de A. A odontologia no plano federal. Rio de Janeiro: Imprensa Nacional; 1986.

26. França GV de. Deontologia médica. In: França GV de. Medicina legal. 7a ed. Rio de Janeiro: Guanabara Koogan; 2004. p.433-79.

27. Giachetti NJ. Preceitos legais que interessam ao exercício da odontologia. São Paulo: Laboratórios Lysanda; 1960.

28. Graça-Leite V da. Odontologia legal. Salvador: Era Nova; 1962

29. Juramento Hipocrático [Citado em 4 nov. 2010] Disponível em: http://www.cremesp.com.br/ ?siteAcao $=$ Historia\&esc $=3$

30. Menezes JDV de. Normas para o exercício legal. In Samico AHR, Menezes JDV de, Silva M da. Aspectos éticos e legais do exercício da Odontologia. Rio de Janeiro: Conselho Federal de Odontologia; 1990. p.21-6.

31. Phillips $P$. The priceless ingredients of our profession. J Am Dent Assoc. 1960;60(3):281-4.

32. Samico AHR. O exercício da profissão odontológica In: Samico AHR, Menezes JDV de, Silva M da. Aspectos éticos e legais do exercício da odontologia. Rio de Janeiro: Conselho Federal de Odontologia; 1990. p.13-20.

33. Vanrell JP. A odontologia legal e suas relações com o direito. In: Vanrell JP. Odontologia legal \& antropologia forense. Rio de Janeiro: Guanabara Koogan; 2002. p.7-12. 